\title{
Clinical Update on Spondyloarthritis
}

\author{
Isabelle Hébert MD FRCPC, Isabelle Fortin MD
}

\begin{tabular}{l}
$\begin{array}{l}\text { About the Authors } \\
\text { Isabelle Hébert (far left) is a general internist in Chandler, Gaspé Peninsula, Quebec. She is the } \\
\text { head of the Specialized Medicine Department in Chandler and president of the internal medicine } \\
\text { French board of the Royal College of Physicians and Surgeons of Canada. Isabelle Fortin is a } \\
\text { rheumatologistworking in Rimouski, Quebec. Her interests are in inflammatory diseases, research, } \\
\text { and models of care. Correspondence may be directed to ihebert@globetrotter.net. }\end{array}$ \\
\hline
\end{tabular}

$\mathrm{T}$

he spondyloarthritides encompass various clinical manifestations. The hallmark of the spondyloarthropathies is inflammatory axial and sacroiliac (buttock) pain. Associated findings include peripheral arthritis, uveitis, conjunctivitis, enthesitis, and psoriasis. Human leukocyte antigen (HLA) B27 is positive in a majority of patients. Radiographic abnormalities appear first on vertebral column/sacroiliac magnetic resonance imaging (MRI) and many years later on radiography, which makes the diagnosis challenging. Of course, rheumatoid factor is negative - hence the term seronegative arthritis. Other clinical clues that help identify this disease's spectrum are a family history of ankylosing spondylitis (AS), psoriasis, or inflammatory bowel disease (IBD); intestinal or genitourinary symptoms; or the presence of psoriasis. All this heterogeneity makes an early diagnosis difficult.

\section{Clinical Findings}

The first symptoms are inflammatory axial and sacroiliac (radiating to buttocks) pain, lasting for more than 3 months. By definition, inflammatory back pain is worse in the morning and associated with stiffness lasting more than 30 minutes, causes awakening at night, and is relieved by exercise and/or nonsteroidal anti-inflammatory drugs (NSAIDs). Peripheral arthritis (synovitis with swollen, warm, and painful joints) may accompany the axial pain; in some cases, axial pain may be absent.

This appendicular arthritis usually presents with an oligoarticular and asymmetrical pattern, involving lower-limb large and medium-sized joints. On some occasions, it presents as a symmetrical polyarthritis, involving small metacarpophalangeal and proximal interphalangeal joints of the hands or metatarsophalangeal and proximal interphalangeal joints of the feet, thus mimicking rheumatoid arthritis. Dactylitis is another peripheral manifestation characteristic of spondyloarthropathies in general. This condition, also called "sausage digit," is defined by a painful and erythematous swelling of an entire digit.

Regarding psoriatic arthritis, five patterns of joint involvement have been described: distal arthritis, in which the distal interphalangeal joints are involved; asymmetric oligoarthritis, with less than five joints implicated; symmetric polyarthritis, mimicking rheumatoid arthritis; arthritis mutilans, in which deforming and destructive arthritis occurs (rare); and, finally, spondyloarthritis.

In IBD, the oligoarticular form accompanies flare-ups and lasts only a few weeks, but the axial manifestations present independently, occasionally occurring a few years before intestinal manifestations and sometimes lasting many months.

Another important clinical clue regarding spondyloarthritis is the presence of enthesopathy, which is inflammation at the bone insertion of tendons. Enthesopathy is responsible for costochondral pain (costochondritis). The main peripheral clinical location is the heel (the inferior part at the insertion of the plantar fascia on the calcaneus and the posterior part at the insertion of the Achilles tendon on the calcaneus). ${ }^{1}$ But many other sites can be implicated, as shown in Figure $1 .^{2}$

Cutaneous findings in reactive arthritis include keratoderma blennorrhagica, balanitis circinata, and oral ulcers. Erythema nodosum may be the first clinical manifestation, especially with IBD; however, pyoderma gangrenosum and hidradenitis suppurativa are rare coexisting disorders $(0.75 \%$ of patients in a cohort of 2,402 persons) associated with IBD. ${ }^{3}$ Of course, psoriasis accompanies psoriatic arthritis in the majority of cases. Sometimes, plaques are not readily visible (and are hidden on the scalp, umbilicus, buttocks, genitals) and nail manifestations may be subtle. Psoriatic arthritis antedates the skin lesions in about $13-17 \%$ of patients. ${ }^{4}$

Regarding eye involvement, uveitis can be seen with all 
Box 40 Maastricht Ankylosing Spondylitis Enthesitis Score (MASES)

13 sites:

- Costochondral 1 right/left (a)

- Costochondral 7 right/left (b)

- Spina iliaca anterior superior right/left (c)

- Crista iliaca right/left (d)

- Spina iliaca posterior right/left (e)

- Processus spinosus L5 (f)

- Achilles tendon, proximal insertion right/left $(\mathrm{g})$

- No grading

- All sites are scored as 0 or 1 .

- The MASES is the sum of all site scores (from 0 to 13).

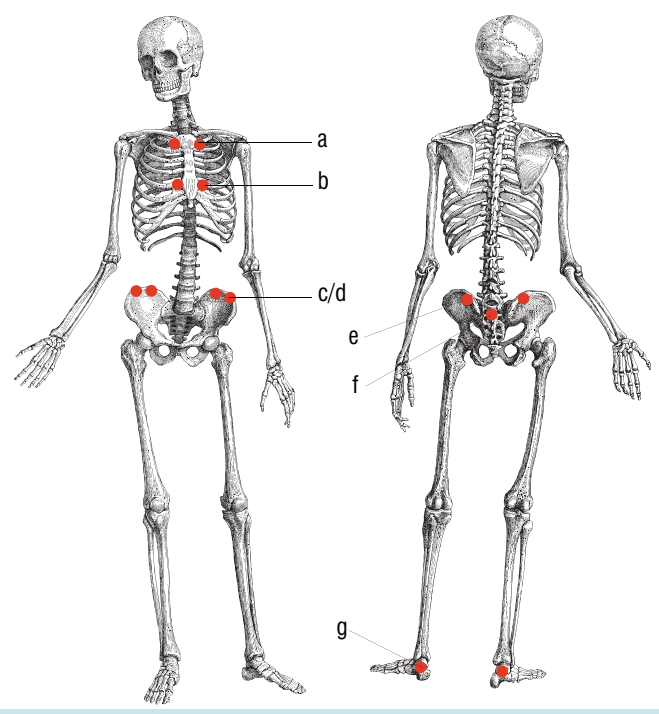

Figure 1. Maastricht Ankylosing Spondylitis Enthesitis Score (MASES). Source: Adapted from Heuft-Dorenbosch et al. ${ }^{2}$

spondyloarthropathy subgroups. Patients present with blurred vision in cases of posterior uveitis, and with eye pain and redness in cases of anterior uveitis (iritis). Other ocular manifestations include conjunctivitis, scleritis, and episcleritis.

The gastrointestinal tract may of course be implicated. In the case of reactive arthritis, an acute episode of infectious diarrhea or sexually transmitted disease triggers an oligoarthritis. For chronic diarrhea associated with arthritis, the general internist's differential diagnosis includes IBD, celiac disease, Whipple's disease, and Behçet's syndrome. Indeed, asymptomatic inflammation of the ileum is present in about $20 \%$ of patients with spondyloarthropathy.

Cardiac problems are rare but are typically associated with AS and reactive arthritis and include aortitis, aortic insufficiency, and heart block. ${ }^{5}$ Pulmonary involvement may also occur: patients with AS may present with dyspnea owing to chest expansion reduction (restrictive syndrome), which is due to costovertebral rigidity. ${ }^{6}$ Patients with AS may also present with pulmonary fibrosis or fibrocavitary disease, which can be complicated by infection with Aspergillus or Mycobacterium. ${ }^{7}$

Neurological symptoms sometimes also occur because of spine and syndesmophyte fractures, which can produce cauda equina syndrome as well as spinal stenosis. Spinal fusion may also occur if the patient has had long-standing disease, with a marked reduction in spinal mobility and a subsequent "bamboo spine" appearance.

\section{Physical Examination Findings}

Pertaining to spondyloarthritis, these are the main physical examination findings in a patient with established axial involvement (for abnormal values, see details about the BASMI, below):

- An increased occiput-to-wall distance or increased tragusto-wall distance (normal at $0 \mathrm{~cm}$ )

- A reduced cervical rotation and lateral flexion

- A reduced chest wall expansion (normal at $>5 \mathrm{~cm}$ )

- A reduced thoracic lateral flexion, a reduced lumbar lordosis, and an abnormal Schober test (normally passes from 10 to $15 \mathrm{~cm}$ )

- A reduced intermalleolar distance

All these findings have been included in a scale called the Bath Ankylosing Spondylitis Metrology Index (BASMI). ${ }^{8}$ In the BASMI, findings are rated as mild, moderate, and severe and are assigned points accordingly:

- Lateral lumbar flexion: mild $=>10 \mathrm{~cm}(0$ points $)$, moderate $=5-10 \mathrm{~cm}(1$ point $)$, and severe $=<5 \mathrm{~cm}$ (2 points)

- Tragus-to-wall distance: mild $=<15 \mathrm{~cm}$ (0 points), moderate $=15-30 \mathrm{~cm}$ (1 point), and severe $=>30 \mathrm{~cm}$ (2 points)

- Lumbar flexion ( modified Schober): mild $=>4 \mathrm{~cm}$ ( 0 points), moderate $=2-4 \mathrm{~cm}$ ( 1 point $)$, and severe $=<2 \mathrm{~cm}$ ( 2 points)

- Maximal intermalleolar distance: mild $=>100 \mathrm{~cm}$

( 0 points), moderate $=70-100 \mathrm{~cm}$ (1 point), and severe $=<7 \mathrm{~cm}$ ( 2 points $)$

- Cervical rotation: mild $=>70^{\circ}(0$ points $)$, moderate $=20-70^{\circ}$ ( 1 point $)$, and severe $=<20^{\circ}$ ( 2 points $)$

The sum of the assessments gives the result for the BASMI.

Of course, examination of the sacroiliac joints is also useful but is weakly reproducible. Nevertheless, if many sacroiliac 
manoeuvres are combined, the results are generally valid and reproducible. ${ }^{9,10}$

Clinical findings associated with spondyloarthropathy such as peripheral arthritis, enthesopathy, and ocular and cutaneous disease should also be identified.

\section{Clinical Questionnaires}

The Bath Ankylosing Spondylitis Disease Activity Index (BASDAI) and the Bath Ankylosing Spondylitis Function Index (BASFI) are two very useful clinical questionnaires. BASFI evaluates patient symptoms and functionality in everyday life. BASDAI is a good indicator of disease activity. At each visit, these questionnaires serve as tools to measure a patient's clinical progression or regression. ${ }^{8}$ They can be found easily on the web or in the Assessment of Spondyloarthritis International Society (ASAS) Handbook: A Guide to Assess Spondyloarthritis. ${ }^{8}$

\section{Laboratory Tests}

HLA-B27 is not the only genetic marker implicated in spondyloarthritis, but it is a major genetic risk factor. This is why it has been included in the ASAS classification criteria for both patients with axial spondyloarthritis and those with peripheral features only (see below). ${ }^{8,11}$

$\mathrm{C}$-reactive protein is also useful but is not always high. It is elevated in only half of patients with AS, and it is associated with more aggressive disease. ${ }^{12}$ However, in our practice, C-reactive protein is elevated in much fewer than half of the cases. The role of erythrocyte sedimentation rate is less clear. ${ }^{12}$

\section{Imaging}

\section{Magnetic Resonance Imaging}

The key features in spondyloarthropathy are inflammation and new bone formation. ${ }^{8,13}$ At first, active inflammation is only visible on MRI, especially at the sacroiliac joints, and is represented by bone marrow edema. Chronic inflammation of those joints is seen as sclerosis, erosions, fat deposition, and bony bridges/ankylosis. Inflammation can also be found all the way down the axial skeleton, involving vertebral bodies, intervertebral discs, costovertebral and costotransverse and facet joints, and spinal ligaments. ${ }^{8}$ MRI can detect early abnormalities associated with spondyloarthropathy earlier than routine radiography can.

\section{Radiography}

Radiography can detect only chronic bony changes and new bone formation (ankylosis and syndesmophytes), which are consequences of inflammation. ${ }^{8}$ Grading of radiologic sacroiliitis is made according to modified New York criteria. ${ }^{8}$

One should also perform radiography of the cervical and lumbar spine. Changes in the thoracic spine are technically more difficult to detect, so ASAS does not support its routine use. $^{8}$

\section{Computed Tomography Scan}

Computed tomography (CT) scans can detect chronic bony changes but at the cost of higher doses of radiation for the patient. Nevertheless, CT can be useful for differentiation between diffuse idiopathic skeletal hyperostosis (DISH) and spondyloarthropathy. ${ }^{8}$

\section{Scintigraphy}

Scintigraphy presents limited sensitivity and specificity and is no longer used for the diagnosis of spondyloarthropathy. ${ }^{8}$ It has been replaced by MRI for the detection of inflammation.

\section{How to Diagnose a Spondyloarthropathy}

Updated ASAS criteria for the diagnosis of axial spondyloarthropathy have been published recently. ${ }^{11}$ Generally, in order to meet the criteria, a patient should have back pain lasting more than 3 months and an age at onset of less than 45 years. In addition, the patient should present with sacroiliitis on imaging plus one or more spondyloarthropathy feature or

\section{Table 1. Assessment in Spondyloarthritis International Society Classification Criteria for Axial Spondyloarthritis*}

\section{Sacroiliitis on imaging ${ }^{\dagger}$ plus $\geq 1$ of the SpA features ${ }^{\ddagger}$}

Or

HLA-B27 plus $\geq 2$ other SpA features

Sacroiliitis on imaging:

- Active (acute) inflammation on MRI highly suggestive of sacroiliitis associated with $\mathrm{SpA}$

- Definite radiographic sacroiliitis as per the modified New York criteria

\$SpA features:

- Inflammatory back pain

- Arthritis

- Enthesitis (heel)

- Uveitis

- Dactylitis

- Psoriasis

- Crohn's disease/colitis

- Good response to NSAIDs

- Family history for SpA

- HLA-B27

- Elevated CRP

$\mathrm{CRP}=\mathrm{C}$-reactive protein; $\mathrm{HLA}=$ human leukocyte antigen; $\mathrm{MRI}$ = magnetic resonance imaging; NSAIDs = nonsteroidal anti-inflammatory drugs; SpA = spondyloarthritis.

*In patients with $>3$ months back pain and age at onset of $<45$ years.

Source: Adapted from Van Der Heijde et al."11 


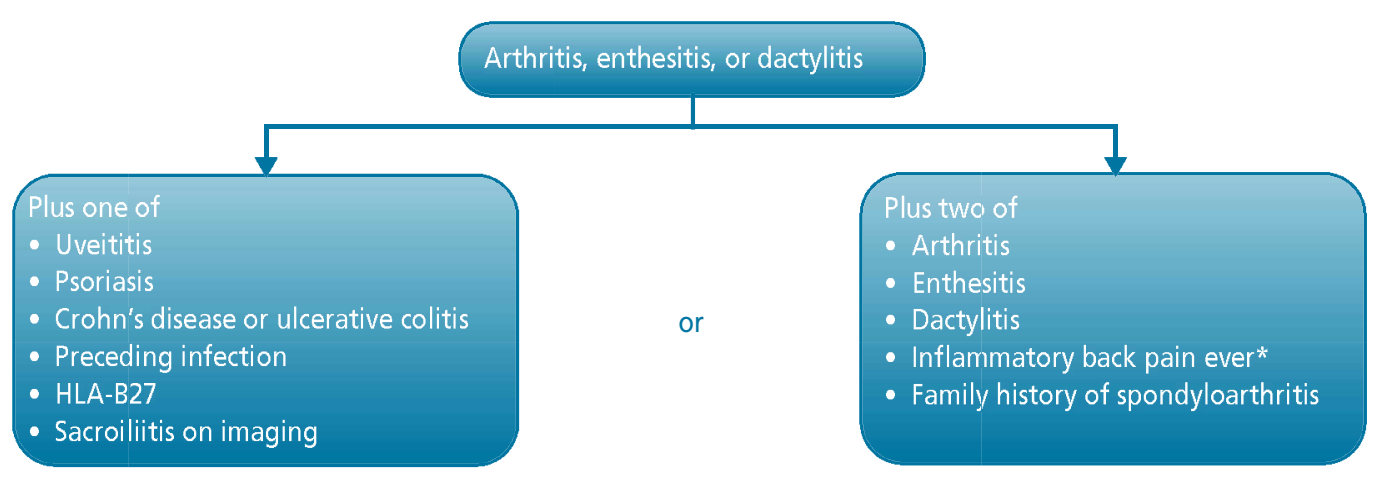

Figure 2. Assessment of Spondyloarthritis International Society criteria for peripheral spondyloarthritis in patients with peripheral features only. HLA = human leukocyte antigen.

*Inflammatory back pain ever" refers to an episode of back pain that is worse in the morning and can even wake up the patient at night; it is relieved by activity. (In the worst-case scenario, this pain can be present all day.)

Source: Adapted from Rudwaleit and colleagues. ${ }^{14}$

the patient should have HLA-B27 plus two or more spondyloarthropathy features (Table 1). ${ }^{11}$

ASAS criteria for the diagnosis of peripheral spondyloarthritis in patients with only peripheral features have also been established (Figure 2). ${ }^{14}$

\section{How Do I Treat My Patient?}

According to a Cochrane systemic review of the literature, treatment of patients with spondyloarthritis should first include physiotherapy; supervised group therapy has been shown to be better than home exercise. ${ }^{8,15}$ However, it is unclear if a patient should exercise during flare-ups of the disease or at a very early stage.

Second, NSAIDs should be used as a baseline treatment in spondyloarthritis as they can reduce pain and stiffness rapidly in $48-72$ hours. $^{8}$ The response to NSAIDs can be a clue to elucidate a diagnosis of spondyloarthritis (see diagnostic criteria above). The investigators of one study even suggested that NSAIDs could delay radiological progression of spine disease when given continuously over a 2-year period, compared with disease progression in patients receiving NSAIDs on demand only. ${ }^{16}$ Unfortunately, many side effects preclude the long-term use of this kind of medication.

Local steroid injections can be considered for a specific joint or area of enthesitis. Systemic steroids may bring some pain and stiffness relief, but the use of those agents in axial disease is not supported by evidence. ${ }^{8}$

Disease-modifying anti-rheumatic drugs (DMARDs) have some efficacy for peripheral arthritis but have not shown any proven benefit for axial spondyloarthritis, enthesopathy, or dactylitis. ${ }^{17}$ For psoriatic peripheral arthritis, one can choose to use methotrexate (to treat psoriasis at the same time), sulfasalazine, or leflunomide. Cyclosporine is rarely used in our practice for psoriatic arthritis. Peripheral arthritis associated with IBD may respond to methotrexate, sulfasalazine, or leflunomide, but the latter is not used for treatment of IBD. Azathioprine or mercaptopurine, used for IBD, does not have a noteworthy effect on arthritis. According to ASAS, sulfasalazine remains the preferred DMARD for the treatment of peripheral arthritis associated with spondy-loarthropathy. ${ }^{8}$

A major advance in the fight against spondyloarthritis has been the introduction of anti-tumour necrosis factor (TNF) drugs on the market. These drugs target not only axial and peripheral arthritis but also enthesopathy and extra-articular features, in particular uveitis. According to ASAS, before initiating an anti-TNF medication for axial disease, a patient's BASDAI must be $4+$ and the patient must have failed a trial of at least two NSAIDs over a 4-week period in total at maximum recommended or tolerated dose. Some payers require a 3-month trial per NSAID (again, a trial of at least two NSAIDs) for axial involvement prior to granting coverage for biologic agents. For peripheral arthritis, the patient must have had an adequate therapeutic trial of a DMARD, preferably sulfasalazine. ${ }^{11}$

Infliximab, etanercept, adalimumab, or golimumab can be used in spondyloarthropathy, with some caveats. Golimumab is approved for only AS and psoriatic arthritis. IBD does not respond to etanercept, ${ }^{18}$ and the efficacy of this anti-TNF blocker may be lower or slower in psoriasis treatment than that of other anti-TNF drugs. ${ }^{19,20}$ Golimumab, infliximab, and adalimumab might work better for dactylitis and enthesitis. ${ }^{21-26}$ Finally, infliximab and adalimumab are the only TNF inhibitors shown to reduce uveitis flares. ${ }^{27,28}$ Etanercept has not been shown to be as effective for this indication. ${ }^{29,30}$ There is no official 


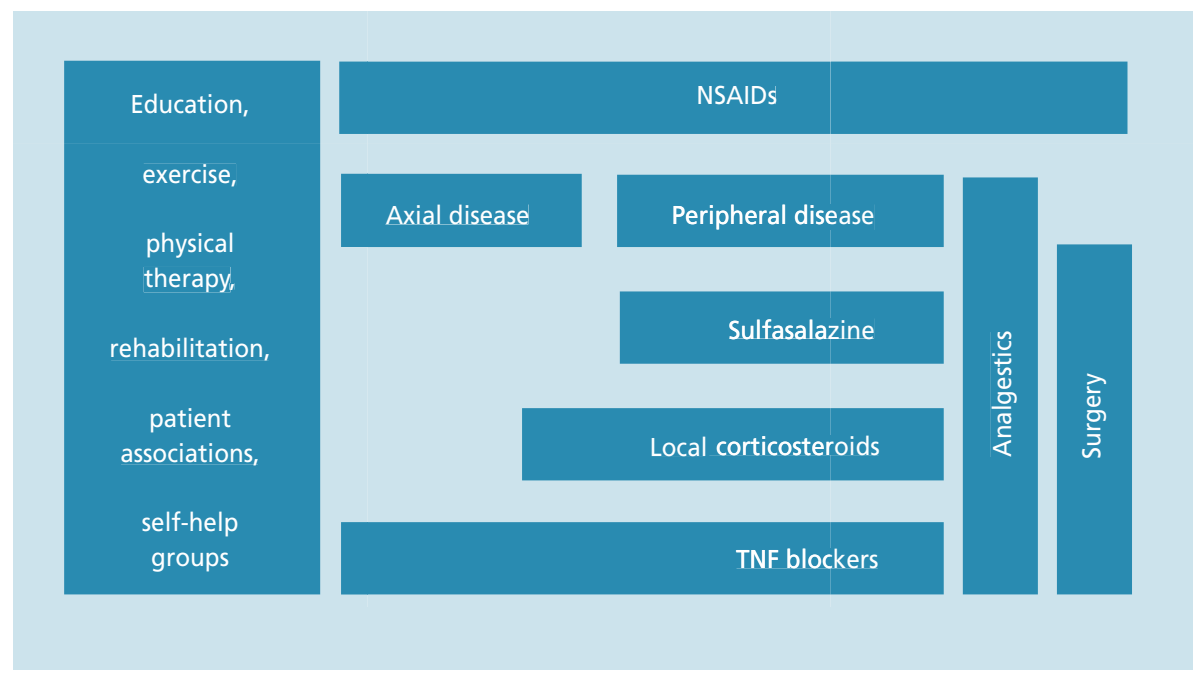

Figure 3. Global treatment approach for spondyloarthritis. TNF = tumour necrosis factor. Source: Adapted from Sieper et al. ${ }^{8}$

recommendation regarding the combination of anti-TNF drugs with DMARDs, as data are lacking. Nevertheless, if a patient fails to respond to a first anti-TNF agent, some experts use a second anti-TNF blocker combined with methotrexate.

Other treatments for spondyloarthritis have shown some benefit. Abatacept, a T-cell co-stimulation blocker, improves psoriatic arthritis but has no significant effect on enthesitis or dactylitis. Certolizumab pegol, an anti-TNF blocker, is being used in some countries to treat Crohn's disease and associated arthritis. In a phase-3, 24-week study called RAPID-PsA, certolizumab treatment was also associated with a significant reduction of signs and symptoms associated with psoriatic arthritis, with $60 \%$ of patients reaching PASI-75 (a 75\% improvement in their Psoriasis Area and Severity Index score) at 24 weeks. ${ }^{31}$ Another molecule, an interleukin-12/23 inhibitor, ustekinumab, demonstrated promising results in psoriatic arthritis in the phase 3 PSUMMIT I study, with $49.5 \%$ of patients reaching a 20\% improvement from baseline (ACR 20 score) at 24 weeks. ${ }^{32}$

The global treatment approach for spondyloarthritis is summarized in Figure $3 .{ }^{8}$

\section{Conclusion}

The understanding of the spondyloarthritides is growing, as are the treatment options. But there is still a lot of work to do to control this disease. Despite the addition of anti-TNF drugs, more progress has to be made regarding radiographic progression. Indeed, in some studies, anti-TNF blockade failed to slow progression of syndesmophytes and ankylosis in spondyloarthritis. Maybe the reason why this treatment failure occurred is that some patients were treated too late with antiTNF drugs. Moreover, recent trials with the TNF inhibitors and NSAIDs have shown that syndesmophtye formation was reduced. ${ }^{16,33,34}$ These results show promise for future generations of patients treated earlier in their disease course.

\section{References}

1. Dougados M, Baeten D. Spondyloarthritis. Lancet 2011;377(9783):212737.

2. Heuft-Dorenbosch L, Spoorenberg A, van Tubergen A, et al. Assessment of enthesitis in ankylosing spondylitis. Ann Rheum Dis 2003;62:127-32.

3. Farhi D, Cosnes J, Zizi N, et al. Significance of erythema nodosum and pyoderma gangrenosum in inflammatory bowel diseases: a cohort study of 2402 patients. Medicine (Baltimore) 2008;87:281.

4. Gladman DD, Shuckett R, Russell ML, et al. Psoriatic arthritis (PSA) - an analysis of 220 patients. Q J Med 1987;62:127.

5. Flores D, Marquez J, Garza M, Espinoza LR. Reactive arthritis: newer developments. Rheum Dis Clin North Am 2003;29(1):37-59.

6. Boushea DK, Sundstrom WR. The pleuropulmonary manifestations of ankylosing spondylitis. Semin Arthritis Rheum 1989;18:277.

7. Lanthier L, Liang P. Spondylarthropathies séronégatives. In: Lanthier L et al., eds. Guide Pratique de Médecine Interne. Trois-Rivières (QC): Les Éditions Formed Inc; 2009.

8. Sieper J, Rudwaleit M, Baraliakos X, et al. The Assessment of Spondyloarthritis International Society (ASAS) handbook: a guide to assess spondyloarthritis. Ann Rheum Dis 2009;68 Suppl 2:ii1-44

9. Tremblay JL. L'examen musculosquelettique. Montréal (PQ): Les presses de l’Université de Montréal; 2009.

10. Van der Wurff P, Hagmeijer RH, Meyne W. Clinical tests of the sacro-iliac joint - a systemic methodological review: reliability. Man Ther 2000;5(1):30-36.

11. Van Der Heijde D, Sieper J, Maksymowych WP, et al. 2010 Update of the international ASAS recommendations for the use of anti-TNF agents in patients with axial spondyloarthritis. Ann Rheum Dis 2011;70:905-8.

12. Spoorenberg A, Van Der Heijde D, de Klerk E, et al. Relative value of erythrocyte sedimentation rate and C-reactive protein in assessment of disease activity in ankylosing spondylitis. J Rheumatol 1999;26:980-4.

13. Braun J, Sieper J. Ankylosing spondylitis. Lancet 2007;369:1379-90. 
14. Rudwaleit M, Van Der Heijde D, Landewé R, et al. The Assessment of Spondyloarthritis International Society classification criteria for peripheral spondyloarthritis and for spondyloarthritis in general. Ann Rheum Dis 2011;70:25-31.

15. Dagfinrud H, Kvein TK, Hagen KB. Physiotherapy interventions for ankylosing spondylitis. Cochrane Database Syst Rev 2008;1:CD002822.

16. Wanders A, Van Der Heijde D, Landewé R, et al. Nonsteroidal antiinflammatory drugs reduce radiographic progression in patients with ankylosing spondylitis: a randomized clinical trial. Arthritis Rheum 2005;52:1634-36.

17. Ritchlin CT, Kavanaugh A, Gladman DD, et al. Treatment recommendations for psoriatic arthritis. Ann Rheum Dis 2009;68:1387-94.

18. Heldman F, Dybowski F, Saracbasi-Zender E, et al. Update on biologic therapy in the management of axial spondyloarthritis. Curr Rheumatol Rep 2010;12:325-31.

19. Gossec L, Smolen JS, Gaujoux-Viala C, et al. European League Against Rheumatism recommendations for the management of psoriatic arthritis with pharmacological therapies. Ann Rheum Dis 2012;71:4-12, 21.

20. Mease PJ, Goffe BS, Metz J, et al. Etanercept in the treatment of psoriatic arthritis and psoriasis: a randomised trial. Lancet 2000;356:385-90.

21. Helliwell PS. Therapies for dactylitis in psoriatic arthritis. A systematic review. J Rheumatol 2006;33:1439-41.

22. Kavanaugh A, Mease P. Treatment of psoriatic arthritis with tumor necrosis factor inhibitors: longer-term outcomes including enthesitis and dactylitis with golimumab treatment in the Longterm Extension of a Randomized, Placebo-controlled Study (GO-REVEAL). J Rheumatol Suppl 2012;89:90-3. doi: 10.3899/jrheum.120254.

23. Baraliakos X, Braun J. Anti-TNF- $\alpha$ therapy with infliximab in spondyloarthritides. Expert Rev Clin Immunol 2010;6(1):9-19.

24. Van der Heijde D, Kivitz A, Schiff MH, et al. Efficacy and safety of adalimumab in patients with ankylosing spondylitis: results of a multicenter, randomized, double-blind, placebo-controlled trial. Arthritis Rheum 2006;54(7):2136-46.

25. Gladman DD, Sampalis JS, Illouz O, Guérette B. Responses to adalimumab in patients with active psoriatic arthritis who have not adequately responded to prior therapy: effectiveness and safety results from an openlabel study. J Rheumatol 2010;37(9);1898-906.

26. Rudwaleit M, Claudepierre P, Wordsworth P, et al. Effectiveness, safety, and predictors of good clinical response in 1250 patients treated with adalimumab for active ankylosing spondylitis. J Rheumatol 2009;36:1-8.

27. Rudwailet M, Rodevand E, Holck P, et al. Adalimumab effectively reduces the rate of anterior uveitis flares in patients with active ankylosing spondylitis: results of a prospective open-label study. Ann Rheum Dis 2009;68:696-701.

28. Braun J, Baraliakos X, Listing J, et al. Decreased incidence of anterior uveitis in patients with ankylosing spondylitis treated with the anti-tumor necrosis factor agents infliximab and etanercept. Arthritis Rheum 2005;52:2447-51.

29. Cobo-Ibáñez T, del Carmen Ordóñez M, Muñoz-Fernández S, et al. Do TNF-blockers reduce or induce uveitis? Rheumatology (Oxford) 2008;47(5):731-2. doi: 10.1093/rheumatology/ken091.

30. Takeuchi M. A systematic review of biologics for the treatment of noninfectious uveitis. Immunotherapy 2013;5(1):91-102.

31. Mease PJ et al. Effect of certolizumab pegol on signs and symptoms in patients with psoriatic arthritis: 24 week results of a phase 3 double blind randomized placebo-controlled study (RAPID-PSA) [abstract LB0001]. Presented at the European League Against Rheumatism (EULAR) Congress; 2012 Jun 6-9; Berlin, Germany.

32. McInnes IB et al. [abstract OP0158]. Ustekinumab in Patients With Active Psoriatic Arthritis: Results of the Phase 3, Multicenter, Double-

Blind,\#Placebo-Controlled PSUMMIT I Study. Presented at the European League Against Rheumatism (EULAR) Congress; 2012 Jun 6-9; Berlin, Germany

33. Baraliakos X, Heldmann F. Inflammation and fatty degeneration are of similar importance for new bone formation in patients with ankylosing spondylitis treated with infliximab or other anti-TNF agents over 5 years. Ann Rheum Dis 2012;71(Suppl 3):113.

34. Lopez Velandia JG, et al. Absence of radiographic progression at two years in a cohort of patients with non-radiographic axial spondyloarthritis treated with TNF $\alpha$ blockers. Ann Rheum Dis 2012;71(Suppl 3):249. 